\title{
Evidence-based interventions in primary care following acute coronary syndrome in Australia and New Zealand: a systematic scoping review
}

Manavi M. Bhagwat ${ }^{1,2^{*}}$, John A. Woods ${ }^{1}$, Mithilesh Dronavalli ${ }^{1}$, Sandra J. Hamilton ${ }^{1}$ and Sandra C. Thompson ${ }^{1}$

\begin{abstract}
Background: Coronary artery disease has a significant disease burden, but there are many known barriers to management of acute coronary syndrome (ACS). General practitioners (GPS) bear considerable responsibility for post-discharge management of ACS in Australia and New Zealand (NZ), but knowledge about the extent and efficacy of such management is limited. This systematic review summarises published evidence from Australia and New Zealand regarding management in primary care after discharge following ACS.

Methods: A search of PubMed, Scopus, CINAHL-Plus and PSYCINFO databases in August 2015 was supplemented by citation screening and hand-searching. Literature was selected based on specified criteria, and assessed for quality using the Mixed Methods Appraisal Tool (MMAT). Extracted data was related to evidence-based interventions specified by published guidelines.

Results: The search yielded 19 publications, most of which reported on quantitative and observational studies from Australia. The majority of studies scored at least $75 \%$ on the MMAT. Diverse aspects of management by GPs are presented according to categories of evidence-based guidelines. Data suggests that GPs are more likely to prescribe ACS medications than to assist in lifestyle or psychological management. GP referral to cardiac rehabilitation varied, and one study showed an improvement in the number of ACS patients with documented ACS management plans. Few studies described successful interventions to improve GP management, though some quality improvement efforts through education and integration of care with hospitals were beneficial. Limited data was published about interventions effective in rural, minority, and Indigenous populations.

Conclusions: Research reflects room for improvement in GP post-discharge ACS management, but little is known about effective methods for improvement. Additional research, both observational and interventional, would assist GPs in improving the quality of post-discharge ACS care.
\end{abstract}

Keywords: Acute coronary syndrome, Australia, Cardiovascular disease, Evidence-based medicine, Ischaemic heart disease, Myocardial infarction, New Zealand, Primary care, Secondary prevention

\footnotetext{
* Correspondence: manavi.bhagwat@gmail.com

${ }^{1}$ Western Australian Centre for Rural Health, The University of Western

Australia (M706), 35 Stirling Highway, Crawley, Western Australia 6009,

Australia

${ }^{2}$ Georgetown University, Washington, DC, USA
}

(c) The Author(s). 2016 Open Access This article is distributed under the terms of the Creative Commons Attribution 4.0 International License (http://creativecommons.org/licenses/by/4.0/), which permits unrestricted use, distribution, and reproduction in any medium, provided you give appropriate credit to the original author(s) and the source, provide a link to the Creative Commons license, and indicate if changes were made. The Creative Commons Public Domain Dedication waiver (http://creativecommons.org/publicdomain/zero/1.0/) applies to the data made available in this article, unless otherwise stated. 


\section{Background}

Modern medical treatments like coronary revascularization for acute coronary events have benefits of high rates of patient recovery but there are high risks of hospital readmission and mortality for survivors. For example, a recent follow up of patients undergoing percutaneous coronary interventions found that $4.7 \%$ were readmitted within 30 days, and nearly half of these $(2.1 \%)$ were classified as ACS/heart failure related [1]. For this reason, it is imperative that patients receive proper medical management of coronary risk factors and support for the adoption of a healthy lifestyle [2-4].

Based upon good evidence, guidelines recommend comprehensive post-discharge ACS care that covers management of biomedical and lifestyle risk factors, pharmacotherapy, psychological factor assessment, and assistance in initiating and maintaining behaviour change $[5,6]$ (Table 1). Interventions recommended by the guidelines are known to reduce patients' risk of subsequent cardiac events [5, 7-9]. However, since hospital stays for ACS are decreasing in length, much of the responsibility for post-discharge management is left to the general practitioner (GP).

The implementation of recommended interventions is imperfect $[10,11]$ as there are many barriers and facilitators to post-discharge management of CVD. ACS is usually treated in-hospital, and so primary care management depends on the receipt of informative discharge

Table 1 Evidence-based interventions for acute coronary syndrome in primary care $[5,6]$

\begin{tabular}{ll}
\hline Category & Specific Areas for GP Actions \\
\hline Lifestyle/Behavioural Risk & Smoking Cessation \\
Factors/Medical Management & Nutrition Advice \\
& Alcohol \\
& Physical activity \\
& Weight Management \\
& Lipid management \\
Pharmacotherapy & Blood pressure management \\
& Diabetes management \\
& Antiplatelet agent prescription \\
& ACEi/ARA prescription \\
& Beta-blocker prescription \\
& Statin prescription \\
& Short-acting nitrate prescription \\
& Depression management \\
Psychological Management & Social Support \\
Behaviour Change & Referral to cardiac rehabilitation \\
& Chest pain action plan \\
\hline
\end{tabular}

$A C E i / A R B$ angiotensin-converting enzyme inhibitor/angiotensin-II receptor blocker summaries from medical specialists. Additionally, comorbidities like diabetes and depression often make ACS management in primary care more complicated [12].

Adherence to these evidence-based guidelines has been shown to vary in different populations [13]. Australia and New Zealand's populations enjoy comparable health status and both have universal public health coverage $[14,15]$. In both these nations, coronary artery disease is a top health system priority. In Australia, coronary heart disease is responsible for over 10,000 deaths every year, and this number is expected to reach 13,675 by the year 2020 [16]. However, several factors complicate ACS management in these nations, with both Australia and New Zealand's health systems having large rural populations. This may require patients to travel considerable distances to access health services like cardiac rehabilitation (CR), and there are known challenges around integration of hospital and primary care management in rural areas. In addition, both nations have significant Indigenous populations that carry a disproportionate burden of CVD $[17,18]$ with poorer socioeconomic circumstances compared to non-Indigenous people [19]. Both Australia and New Zealand's health systems have funding complexity for health services [14, 15] despite significant government funding to support access to healthcare for citizens.

Studies that attempt to document ACS management often focus on particular aspects like drug utilization $[20,21]$ and CR referral and attendance [22]. However, little is known about overall general practice management of ACS, especially in the context of the health systems of Australia and New Zealand. Syntheses of primary care research have been shown to be useful in shaping health policy initiatives [23]. This study aims to synthesize, using a systematic approach, knowledge about evidence-based post-discharge treatment of ACS in primary care settings in Australia and New Zealand.

\section{Methods \\ Information sources and search strategy}

A systematic literature search was conducted using the following electronic databases: PubMed, SCOPUS, PsychINFO and CINAHL. The search terms comprised subject headings specific to databases where applicable, such as Medical Subject Headings (MeSH) in PubMed, as well as synonyms for these terms generated by the authors or listed in the databases. These searches were supplemented by citation screening of retrieved records and additional hand searching.

Records retrieved were those containing search terms related to ACS, patient discharge/post-discharge management, and either primary care, secondary prevention, and/or cardiac rehabilitation (CR). CR was included as a domain in the search strings because, although generally 
defined as medically supervised programs, CR services are sometimes expanded to include many different aspects of post-discharge management of ACS [24]. The literature search was limited to studies conducted in Australia or New Zealand and to journal articles published in the English language from the year 2000 onwards.

The literature search was last conducted on August $18^{\text {th }}, 2015$. An example of a search string is presented in Additional file 1.

\section{Study selection and inclusion criteria}

Duplicates were identified and removed. The remaining titles and abstracts were screened for eligibility and those that did not meet the inclusion criteria (Table 2) were excluded. Two reviewers (JW and MB) conducted this initial screening process independently, with any discrepancies resolved by discussion. Full-texts of the remaining publications were retrieved and assessed by three authors $(\mathrm{MB}, \mathrm{MD}, \mathrm{JW})$ against the inclusion and exclusion criteria. A flow diagram of the literature search and selection process is presented in Fig. 1.

\section{Data extraction and appraisal}

Data extraction was undertaken by all authors utilising a template with studies grouped according to the type of evidence-based primary care intervention they described. Studies were assessed for quality by one author (MB) based on the Mixed Methods Appraisal Tool (MMAT) [25], a method of appraising studies of various designs, in consultation with a second author (JW).

\section{Results}

Of a total of 219 publications identified, 76 underwent full review and 19 publications reporting on 17 studies met the inclusion criteria (Fig. 1). Most studies were Australian $(n=15)$, quantitative $(n=16)$, and observational $(n=16)$. Only one randomized controlled trial was identified and there was only one qualitative study. Few studies examined Indigenous $(n=3)$, other non-Indigenous minority, or rural $(n=5)$ populations. Two studies examined exclusively female populations, and most studies were constructed with patients $(n=15)$ rather than GPs $(n=4)$ as study populations. A description of studies is presented in Table 3. Studies that reported including male and female populations consistently included a majority of male participants $(n=12)$.

Many publications reported studies on efforts to improve patient follow-up care that were directed from hospitals where patients with ACS had been treated, and these contained limited information regarding specific primary care involvement. Findings are reported in Table 4 and below, categorised according to areas of evidence-based management specified by the Cardiac Society of Australia and New Zealand (CSANZ) guidelines [2].

\section{Pharmacotherapy}

Six studies explored various aspects of pharmacological management of ACS in primary care. One recent Australian observational study reported outcomes of patients $(n=12813)$ following a percutaneous coronary

Table 2 Literature screening (PICO) criteria

\begin{tabular}{|c|c|c|}
\hline & Inclusion & Exclusion \\
\hline Population (P) & $\begin{array}{l}\text {-ACS patients } \\
\text {-GPs treating patients post-ACS } \\
\text {-Studies conducted in Australia or New Zealand } \\
\text {-Any age, race, sex }\end{array}$ & $\begin{array}{l}\text {-Other cardiac conditions } \\
\text { - Heart failure } \\
\text {-Atrial fibrillation } \\
\text {-Non-acute coronary artery disease } \\
\text {-Other acute illnesses }\end{array}$ \\
\hline Intervention (I) & $\begin{array}{l}\text { Care/Interventions [5]: } \\
\text {-Pharmacotherapy } \\
\text {-Lifestyle management } \\
\text {-Behaviour change } \\
\text {-Psychological assessment }\end{array}$ & $\begin{array}{l}\text {-Aspects of evidence-based management not } \\
\text { undertaken in a primary care setting }\end{array}$ \\
\hline Comparator (C) & (not applicable) & (not applicable) \\
\hline Outcome $(\mathrm{O})$ & $\begin{array}{l}\text {-Clinical indicators of care, including: } \\
\text {-Medication prescription rates including LLT } \\
\text {-Smoking cessation/advice rates } \\
\text { - Lifestyle advice receipt } \\
\text {-CR referral rates } \\
\text {-Depression, anxiety, stress rates } \\
\text { - Rates of psychological assessment } \\
\text {-Dietary advice rates } \\
\text { - Insights about barriers and facilitators to primary care management }\end{array}$ & $\begin{array}{l}\text {-Comparisons of efficacy of pharmaceuticals } \\
\text {-Indicators measured in hospital or at discharge } \\
\text {-Indicators in pre-hospital care } \\
\text {-CR attendance with no primary care intervention }\end{array}$ \\
\hline Study Design & $\begin{array}{l}\text {-Cohort } \\
\text {-Cross sectional } \\
\text {-Quality improvement } \\
\text {-Quantitative or qualitative studies }\end{array}$ & $\begin{array}{l}\text {-Conference abstracts } \\
\text {-Systematic reviews } \\
\text {-Case reports }\end{array}$ \\
\hline
\end{tabular}




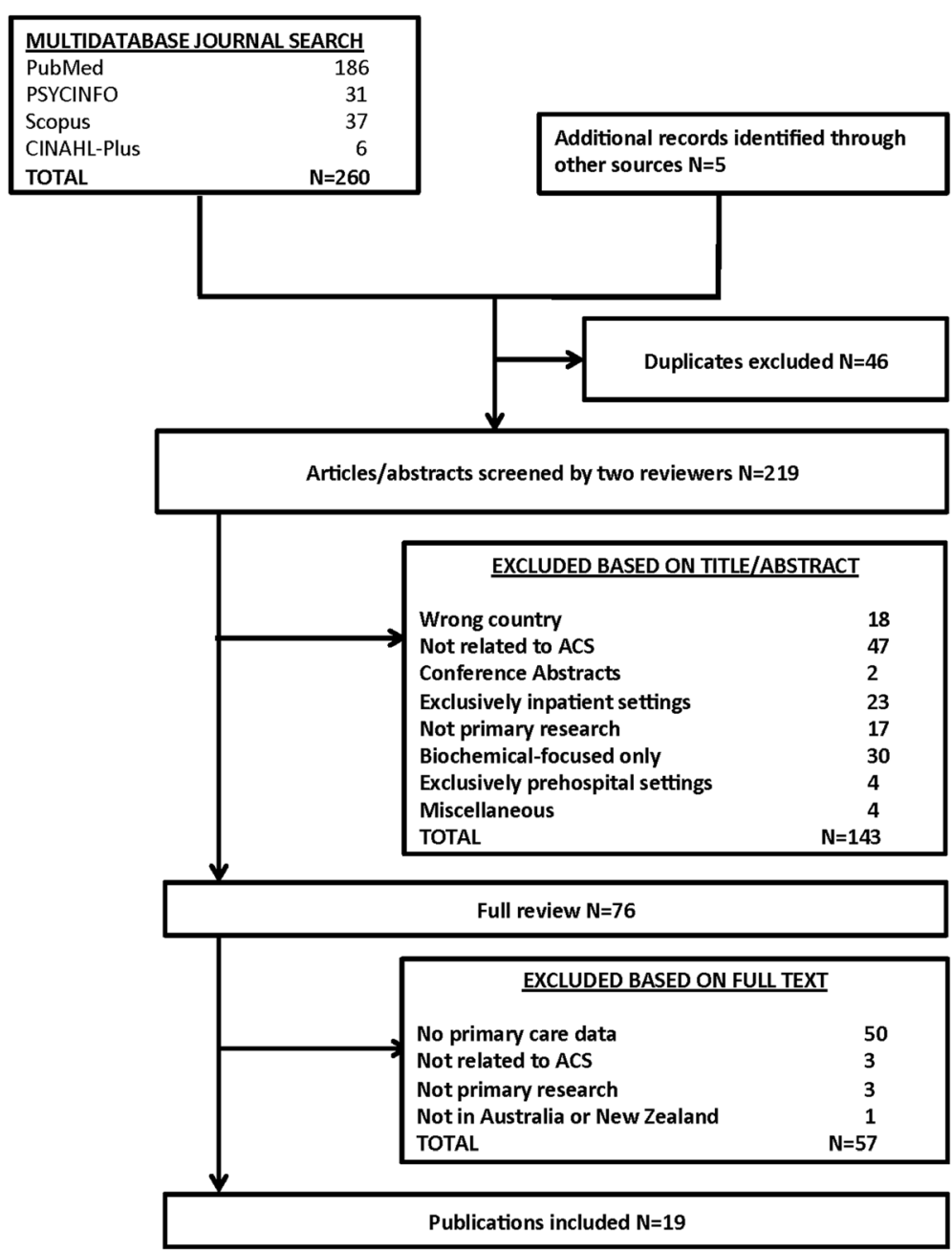

Fig. 1 Flowchart of Search Strategy and Output: PRISMA flowchart

intervention (PCI), the majority in the context of ACS [26]. In 2010, $75 \%$ of patients were taking $\geq 4$ classes of drugs at 12 month follow-up. The study also analysed trend data from 2005 to 2010 and found an increase over time in receipt of all drug classes investigated $(p<0.01)$. Finally, the same study found that females and patients aged $>75$ years had significantly lower rates of medication usage than males and younger patients. Medication use was determined either by patient report or record review. An observational study conducted in New Zealand [27] reported similar rates of medication use at 3-year follow-up $(n=112)$. However, another New Zealand study reported lower rates of medication use in a cohort of coronary artery bypass grafting $(\mathrm{CABG})$ patients $(n=109)$ at three-year follow-up [28]. Wachtel et al. [29] conducted a retrospective analysis of hospital and GP medical records ( $n=34$ patients), and found that GPs generally increased the prescription of evidence-based medications compared to prescription rates at hospital discharge.
Two interventional studies used medication prescription rates at GP follow-up as a clinical indicator to evaluate programs designed to improve post-ACS care [30, 31]. Hickey et al. [30] examined a quality improvement initiative known as the Brisbane Cardiac Consortium (BCC). The intervention included recurrent GP performance feedback from researchers in addition to GP liaison with hospitals regarding patient management. Though the study showed significant improvements in some clinical indicators, it did not report a significant change in prescription rates of medications in primary care follow-up post-intervention $(n=89$ and $n=104$ for 3- and 6- month follow-up, respectively). Scott et al. [31] examined the efficacy of a multi-faceted intervention that included clinical decision support, educational interventions, regular performance feedback, patient self-management strategies, and hospital-community integration. The study found greater prescription rates of aspirin at 3 months post-discharge in intervention 
Table 3 Included studies of primary care post-discharge management of acute coronary syndrome

\begin{tabular}{|c|c|c|c|c|}
\hline First Author (Year) & Study Design & Location & Participants & $\begin{array}{l}\text { Evidence-Based Intervention(s) } \\
\text { (per NHF/CSANZ Guidelines [5]) }\end{array}$ \\
\hline Cole (2014) [26] & Cohort & Melbourne, Australia & $\begin{array}{l}12,813 \mathrm{PCl} \text { patients in the Melbourne } \\
\text { Intervention Group registry }\end{array}$ & Pharmacological management \\
\hline Fernandez (2006) [38] & $\begin{array}{l}\text { Cross-Sectional: consecutive } \\
\text { case series }\end{array}$ & Sydney, Australia & $\begin{array}{l}\text { 202/275 PCl patients who agreed to } \\
\text { participate }\end{array}$ & $\begin{array}{l}\text { Lifestyle management } \\
\text { Psychological management }\end{array}$ \\
\hline Ford (2011) [27] & Cohort with 3 year follow up & Auckland, NZ & 112 ACS patients & $\begin{array}{l}\text { Lifestyle management } \\
\text { Pharmacological management }\end{array}$ \\
\hline Gallagher (2003) [35] & Cohort; Mixed Methods & Sydney, Australia & 196 female CR participants & Behaviour change \\
\hline Hansen (2011) [43] & Qualitative & Tasmania, Australia & $\begin{array}{l}35 \text { ACS patients who were smokers } \\
\text { at time of hospitalisation }\end{array}$ & Lifestyle management \\
\hline Hickey (2004) [30] & Cross-Sectional: indicators of care & Brisbane, Australia & 104 ACS patients & $\begin{array}{l}\text { Lifestyle management } \\
\text { Pharmacological management }\end{array}$ \\
\hline Johnson (2010) [42] & $\begin{array}{l}\text { Retrospective analysis of registry } \\
\text { data combined with (self-report) survey }\end{array}$ & Hunter, Australia & 4971 patients eligible for $C R$ & Lifestyle management \\
\hline Looi (2011) [28] & $\begin{array}{l}\text { Retrospective cohort, data from } \\
\text { hospital CCU database }\end{array}$ & Auckland, NZ & $\begin{array}{l}129 \text { of } 901 \text { patients with ACS who } \\
\text { received inpatient CABG }\end{array}$ & Pharmacological management \\
\hline Mudge (2001) [33] & Retrospective cohort & Brisbane, Australia & $\begin{array}{l}282 \text { of } 352 \text { ACS patients with follow- } \\
\text { up information available }\end{array}$ & $\begin{array}{l}\text { Pharmacological management } \\
\text { Biomedical risk factor management }\end{array}$ \\
\hline Reddy (2008) [39] (further details in [48]) & $\begin{array}{l}\text { Descriptive short report of an intervention } \\
\text { using mixed methods }\end{array}$ & Victoria and South Australia & 36 health professionals & Psychological management \\
\hline Rushford (2007) [36] & Cross-Sectional; Mixed Methods & Melbourne, Australia & 224 female ACS patients & Behaviour change \\
\hline Schrader (2005) [41] & $\mathrm{RCT}$ & Adelaide, Australia & 669 cardiac patients & Psychological management \\
\hline Schulz (2000) [37] & Cross-Sectional: follow-up survey & Horsham, Australia & 79 Ml patients & Behaviour change \\
\hline Scott (2004) [31] & $\begin{array}{l}\text { Before-after evaluation of a quality } \\
\text { improvement program of in-hospital \& } \\
\text { post-discharge care for cardiac patients } \\
\text { (ACS or HF) }\end{array}$ & Brisbane, Australia & $\begin{array}{l}344 \text { ACS patients (of } 662 \text { eligible) } \\
\text { who had evaluable follow-up data }\end{array}$ & $\begin{array}{l}\text { Behaviour change } \\
\text { Pharmacological management }\end{array}$ \\
\hline Toms (2003) [34] & Cross-Sectional & Canberra, Australia & $93 \mathrm{Ml}$ patients & $\begin{array}{l}\text { Behaviour change } \\
\text { Pharmacological management } \\
\text { Lifestyle management }\end{array}$ \\
\hline $\begin{array}{l}\text { a. Wachtel (2008) [29] } \\
\text { b. Wachtel (2008) [40] }\end{array}$ & $\begin{array}{l}\text { Retrospective cohort: analyses of hospital } \\
\text { records \& follow-up in GP clinics }\end{array}$ & Riverland, Australia & $\begin{array}{l}34 \mathrm{Ml} \text { patients with GP records, } \\
\text { of } 55 \text { with hospital records, of } 77 \\
\text { eligible participants }\end{array}$ & $\begin{array}{l}\text { Lifestyle management } \\
\text { Psychological management }\end{array}$ \\
\hline $\begin{array}{l}\text { a. Peterson (2012) [32] } \\
\text { b. Wai (2012) [20] }\end{array}$ & $\begin{array}{l}\text { Before-after evaluation of a quality } \\
\text { improvement program discharge } \\
\text { care (ACS) }\end{array}$ & Australia & $\begin{array}{l}\text { Pre: } 49 \text { hospitals; } 1545 \text { ACS patients } \\
\text { recruited } \\
\text { Post: } 45 \text { hospitals remained in } \\
\text { program; } 1589 \text { ACS patients recruited }\end{array}$ & $\begin{array}{l}\text { Behaviour change } \\
\text { Pharmacological management }\end{array}$ \\
\hline
\end{tabular}

ACS acute coronary syndrome, $C A B G$ coronary artery bypass grafting, $C C U$ coronary care unit, $C R$ cardiac rehabilitation, $H F$ heart failure, $M I$ myocardial infarction, $N Z$ New Zealand, $P C l$ percutaneous coronary intervention, $R C T$ randomised clinical trial 
Table 4 Key findings on primary care post-discharge management of acute coronary syndrome

\begin{tabular}{|c|c|c|c|}
\hline $\begin{array}{l}\text { First Author (Year) } \\
\text { Aim or Research question }\end{array}$ & $\begin{array}{l}\text { Key findings on ACS interventions } \\
\text { in primary care }\end{array}$ & Principal conclusions & $\begin{array}{l}\text { Study Quality Comments } \\
\text { MMAT Score }\end{array}$ \\
\hline Cole (2014) [26] & $\begin{array}{l}\text { Significant increase }(p<0.01) \text { in } \\
\text { frequency of use of all EBM } \\
\text { investigated during calendar period } \\
2005-2010 \\
\text { Medication usage at } 12 \text { months } \\
\text { post-ACS (2010): } \\
\text { Aspirin } 96 \% \\
\text { Clopidogrel } 71 \% \\
\text { DAPT } 68 \% \\
\text { BB } 70 \% \\
\text { ACEi/ARB } 80 \% \\
\text { Statin } 93 \%\end{array}$ & $\begin{array}{l}\text { Guideline-indicated medication use } \\
\text { has increased over the 6-year study } \\
\text { period, but treatment gap remains }\end{array}$ & $\begin{array}{l}\text { - Data extracted from pre-existing ACS } \\
\text { follow-up registry } \\
\text { - } 89 \% \text { follow-up } \\
\text { MMAT: } 100 \%\end{array}$ \\
\hline $\begin{array}{l}\text { Fernandez (2006) [38] } \\
\text { To investigate risk factor status } \\
\text { of post-PCl patients }\end{array}$ & $\begin{array}{l}\text { Risk factor status at } 1 \text { year post-PCl: } \\
\text { Systolic blood pressure above target } 31 \% \\
\text { Total cholesterol above target } 58 \% \\
\text { Smoking } 15 \% \\
\text { BMI above healthy range } 77 \% \\
\text { Obesity } 34 \% \\
\text { Physical activity below target } 48 \% \\
\text { Depression \& anxiety } 25 \% \\
\text { One third of patients erroneously } \\
\text { believed that they had no heart problems }\end{array}$ & $\begin{array}{l}\text { There is inadequate management of } \\
\text { identifiable risk factors among post- } \mathrm{PCl} \\
\text { patients } 12-18 \text { months after } \\
\text { revascularisation }\end{array}$ & $\begin{array}{l}\text { - } 39 \% \text { response among eligible } \\
\text { participants } \\
\text { - Self-reported risk factor status in self- } \\
\text { administered questionnaire } \\
\text { MMAT: } 75 \%\end{array}$ \\
\hline $\begin{array}{l}\text { Ford (2011) [27] } \\
\text { To measure attainment of New } \\
\text { Zealand Guideline Group targets } \\
\text { \& highlight areas of weakness }\end{array}$ & $\begin{array}{l}\text { Risk factor status at } 3 \text { years post-ACS (2010): } \\
\text { Attainment of target blood pressure } 76 \% \\
\text { Smokers who quit } 52 \% \\
\text { BMI in target range } 24 \% \\
\text { HDL levels above target } 74 \% \\
\text { LDL levels below target } 52 \% \\
\text { In } 2010 \text {, at } 3 \text { years post-ACS, } \% \text { of } \\
\text { medications not prescribed by GPs: } \\
\text { Aspirin } 1 \% \\
\text { BB } 6 \% \\
\text { ACEi/ARB } 22 \% \\
\text { Statin } 3 \% \\
\text { GTN spray } 27 \%\end{array}$ & $\begin{array}{l}\text { Concern that GPs were using } \\
\text { outdated guidelines } \\
\text { Mixed achievement of NZGG } \\
\text { program-large treatment gaps for } \\
\text { BMI, HbA1c \& lifestyle } \\
\text { Need for further efforts to improve } \\
\text { diet \& exercise } \\
\text { Weight reduction particularly } \\
\text { challenging—-majority of patients } \\
\text { remained overweight/obese }\end{array}$ & $\begin{array}{l}\text { Reports data by ethnicity } \\
\text { Survivorship bias ( } 26 \text { patients had died) } \\
\text { Interventions implied to be based in } \\
\text { primary care } \\
\text { MMAT: } 75 \%\end{array}$ \\
\hline $\begin{array}{l}\text { Gallagher (2003) [35] } \\
\text { To identify determinants of } \\
\text { women's attendance at CR and } \\
\text { adherence to risk factor modification }\end{array}$ & $\begin{array}{l}\text { At } 12 \text { weeks post-discharge: } \\
\text { - Two-thirds of women referred to CR } \\
\text { - Only one third of the total sample } \\
\text { attended CR } \\
\text { - CABG patients more likely to be referred } \\
\text { than Ml patients } \\
\text { - Lack of employment, age }<55 \text { or }>70 \\
\text { and stressful personal life event decreased } \\
\text { the odds of attending }\end{array}$ & $\begin{array}{l}\text { Good adherence to guidelines on } \\
\text { medications, stress modification \& } \\
\text { smoking } \\
\text { Poorer adherence to diet \& exercise } \\
\text { guidelines }\end{array}$ & $\begin{array}{l}\text { Self-reported outcomes } \\
\text { Non-English speakers excluded } \\
\text { MMAT: } 100 \%\end{array}$ \\
\hline
\end{tabular}
Zealand Guideline Group targets

2010, at 3 years post-ACS, \%

- Two-thirds of women referred to $C R$

- Only one third of the total sample

attended CR

the odds of attending and stressful personal life event decreased
the odds of attending

frequency of use of all EBM

Guideline-indicated medication use

has increased over the 6-year study

stigated during calendar period

Medication usage at 12 month

ACEI/ARB 80

Risk factor status at 1 year post-PC:

Total cholesterol above target $58 \%$

Physical activity below target $48 \%$

Depression \& anxiety $25 \%$

believed that they had no heart problems

concern that GPs were using

Mixed achievement of NZGG

program-large treatment gaps for

Need for further efforts to improve

diet \& exercise

challenging - majority of patients

Poorer adherence to diet \& exercise 
Table 4 Key findings on primary care post-discharge management of acute coronary syndrome (Continued)

Hansen (2011) [43]
To investigate experiences of
ongoing smoking or smoking

cessation post-ACS

Hickey (2004) [30]

To determine whether reliable and valid clinical indicators could

measure ACS primary and hospital care

To determine whether education efforts could improve these clinica indicators

Johnson (2010) [42]

To determine whether self-reported receipt of lifestyle advice from a

health care provider is lower among outpatient cardiac rehabilitation

(OCR) non-attendees and non-referred

patients compared to OCR attendees

Looi (2011) [28]

ure adherence to evidencebased ACS medications post-CABG

Mudge (2001) [33]

To measure prescription of lipidlowering drugs on discharge, and patient adherence at follow up
In 2006-2008, insights about GP smoking

advice to patients post-ACS:

- GP advice sometimes resented and

sometimes appreciated

- GPs more likely to talk to than lecture at

patients compared to specialists

- Doctor patient rapport is important

- Majority of quitters spontaneously quit

with no GP advice

- Failed quitting attempts lead to

hopelessness

In 2002, insights from a program for

hospitals and GPs:

- Robust process and outcome clinical indicators can be developed to assess

primary and hospital care that are relevant

reliable, valid and high impact

- Education program improved 17/40

developed indicators

In 2002-2007, \% of patients receiving lifestyle advice from GPs:

Advised to increase physical activity $71 \%$

Advised to follow a modified fat diet $55 \%$

Advised to quit smoking out of patients

who smoked in last 6 months $88 \%$

In 2006-2007, at 3 years post-CABG, \% of medication usage by patients:

Aspirin 83

BB $62 \%$

ACEi/ARB $43 \%$

Statins $72 \%$

Major adverse cardiological events

(6.2 \%/year): 3 UA, 4 NSTEMI, 6 HF, 5 deaths

In 1998-1999, at 6-18 months post-ACS,

patient status in lipid management:

Did not have lipid measurements $10 \%$

Of patients not prescribed LLD at discharge

patients who did not receive LLD prescription from GP $70 \%$

Of those prescribed LLD on discharge,

patients who remained on the treatment

at GP follow up $88 \%$
Being bombarded with anti-smoking

advice during hospitalisation can

result in patients "turning off"

Anti-smoking advice may have a

positive cumulative effect when

presented well \& at the right time

Pharmacotherapy is underutilised

GPs could better inform patients

about the process of quitting \&

available supports

Suboptimal performance was improved with feedback to GPs.

Economical data collection and timely feedback would improve QI process

Sustainability of this approach limited

by expense and labour

Recommended that referred patients who do not attend CR be identified by their GP and encouraged to participate in home-based CR

Secondary prevention medication usage in ACS patients undergoing CABG was disappointingly low at discharge and worse at follow-up

Identified suboptimal lipid

documentation with poo

communication across hospital-

community interface, poor ongoing

monitoring and dosage adjustment
- Appropriate subject selection

- Low dropout

- No comments on how researchers

could influence interview responses MMAT: $75 \%$

strategies for minimization of ent error

- Found high accuracy through random sampling of audits MMAT: $100 \%$

. $65 \%$ consented to inclusion

- Consenters more likely to be male and undergo CABG

- Analysis based on self-report: patient recall 5 months post-discharge

- Large sample size: used Hunter New

England Heart and Stroke Registry

- Potential response bias

- May underestimate appropriate advice - Considerable missing data MMAT: $100 \%$

. $86 \%$ response rate

- Association between cardiac events and low adherence to cardiac medication was not statistically assessed MMAT: $75 \%$

- No inferential statistics reported - Follow-up information incomplete - Self-report likely to overestimate compliance

MAT. $100 \%$ 
Table 4 Key findings on primary care post-discharge management of acute coronary syndrome (Continued)

Reddy (2008) [39]

To assess the extent to which

evidence-based guidelines have

influenced medical practice with

respect to their experiences in

depression assessment and

management

Rushford (2007) [36]

To assess patient recall of risk factor behaviour modifying intervention at discharge, 2, 4 and 12 months

Schrader (2005) [41]

To evaluate the effect on depressive symptoms in cardiac patients of patient-specific advice to general practitioners regarding management of comorbid depression

Schulz (2000) [37]

To identify factors associated with and predicting attendance of postMI patients at CR program

Scott (2004) [31]

To optimise care of patients with ACS and CHF through a QI intervention across two sectors (hospital and GP) of healthcare

Toms (2003) [34]

To determine whether Phase ॥ outpatient CR participants are more successful at achieving cardiac risk factor targets than non-participants at follow-up post-Ml
Insights from surveys and interviews with GPs: - Little consistency among health professionals on how best to identify and manage depression - Few GPs asked patients about depression regardless of patients' depression score

Insights from study at 12 month follow-up: - CR referral is correlated with attendance - $8 \%$ of women reported wanting more lifestyle advice

In 2000-2001, in a randomized controlled trial: - The intervention had little effect on moderate to severe depression at 12 month - Telephone call to GP from psychiatrist led to a significant decrease in proportion of patients with moderate to severe depression - Multidisciplinary enhanced Primary Care case conference not effective (and difficult to implement)

In 1993-1996, 3.5 years post-Ml:

- $73.4 \%$ referred to CR

- Majority (72 \%) of non-attenders were not referred to $C R$

- Non-referral was significantly associated

with non-attendance

- Attendance significantly associated with referral

In 2000-2002, at 3 months post-ACS, \% of medications prescribed to patients:

Aspirin: (baseline) $82 \%$ (intervention) $89 \%$ Aspirin continuation in those prescribed at discharge: (baseline) $84 \%$ (intervention) $92 \%$ $\beta B$ continuation among those prescribed at discharge: (baseline) $76 \%$ (intervention) $85 \%$

In 2003, at 18-36 months post-Ml:

- Of 36 included CR non-participants (NP)

$53 \%$ not referred by doctor

- CR participants less likely to have total cholesterol > $6.5 \mathrm{mmol} / \mathrm{L}$

- Fewer non-participants were receiving cholesterol lowering medication

- In both groups, approximately $50 \%$ did not achieve target total cholesterol ( $\leq 4.5 \mathrm{mmol} / \mathrm{L})$ - CR participants more likely to be on lipid modifying treatment

- More CR participants exercised regularly
- Wide distribution of guideline-related information was not effective in improving depression management - No agreement on appropriate time and provider for depression screening

Limited advice provided on lifestyle (especially on diet \& physical activity) to women who were obese or inactive. Older women less likely to recall receiving information

Health staff need training in information delivery and communication skills

Recommended screening of hospitalised cardiac patients for depression ansd providing targeted advice to their GPs

Being older, living farther away, living alone and not having private transport wre associated with CR non-attendance Referral to CR also predicted attendance

Implementing systems of decision support, targeted provider education \& performance feedback, patient selfmanagement and hospital-community integration improved patient care particularly when directly controlled by individual clinicians (e.g., prescribing) Those attending CR had better long term outcomes, exercising more and more achieving the goal of a TC $\leq 6.5 \mathrm{mmol} / \mathrm{l}$
- Published short report provides little detail regarding study design and quality appraisal

- Study time frame not reported MMAT: n/a

Response rate $79 \%$

- Good reasons for exclusion

- Detailed assessment of recall on many areas of lifestyle

- No details on how the initial patient education was conducted or its content MMAT: $100 \%$

- No information on what management plans were actually delivered by GPs and no information on antidepressant prescription and service utilisation

- Follow-up below $80 \%$ (78.5 \%) with differential non-reponse in younger separated/divorced patients and smokers - Allocation concealment unclear MMAT: $50 \%$

. $69 \%$ response rate

- Strengths and limitations of study well identified

- Have not defined completion other than to offer second dropout rate of $36 \%$ if attended 6 or fewer sessions

MMAT: $75 \%$

- Not possible to attribute specific processof-care changes to specific QI initiatives within a multifaceted program

- Only significant results reported MMAT: $50 \%$

- Participants resided within $40 \mathrm{~km}$ of Canberra therefore geography less of an issue

- Used TC to assess lipids, not LDL

- Highlight need for data collection

- Low response rate $(51 \%)$

- Limitations of study recognised

- Selection bias likely in those attending CR MMAT: $75 \%$ 
Table 4 Key findings on primary care post-discharge management of acute coronary syndrome (Continued)

- Failure to achieve blood pressure and

weight control similar in both groups

both groups but insufficient sample size to

assess statistical significance

- More CR participants had returned to work

( $92 \%$ vs. $78 \%$ ) but not statistically significant

even after adjusting for age

a. Wachtel (2008) [29]

b. Wachtel (2008) [40]

To determine assessment of lifestyle

and behavioural risk factors in post-Ml

patients in hospital and at GP follow-

up in a rural region of South Australia

a. Wai (2012) [20]

b. Peterson (2012) [32]

To improve the management of ACS

at the point of hospital discharge

across the continuum of care
In 2004-2005:

- Population was $78 \%$ male

- One Aboriginal/Torres Strait Islander patient (2 \%)

- Majority of patients did not receive an

intervention for risk factors

- 5/11 (45 \%) patient smokers received quit

advice, one prescribed NRT

- Higher proportion of patients received

lifestyle interventions in GP practice than

hospital setting, however, with the exception

of smoking this accounted for $7 \%$ of patients

- 16/34 (47 \%) patients had BMI assessed

- 11 were overweight/obese of whom

(18\%) received weight loss advice

In 2009, at a median of 96-day- follow-up (range 49-204):

- $48 \%$ reported using 4 evidence-based medications (EBMs), with a significant decrease in anti-platelet agents, statins, $\beta$ blockers and all 4 EBMs

- $67 \%$ recalled referral to CR of whom $33 \%$

completed CR and $21 \%$ were still attending CR

- 731 GPs (47 \% of patient-nominated GPs)

participated in survey

- $77 \%$ received a discharge summary for patients with ACS at a median time of 3 days ( $0-41$ days) after discharge

- Of these $88 \%$ contained a list of prescribed medications; $81 \%$ included dose titration and duration of therapy and $55 \%$ contained details of ongoing risk management

- $65 \%$ of GPs rated the quality of information

as 'very good' to 'excellent'

$.6 \%$ increase in communication of ACS

management plan to GP

- $18 \%$ increase in patients with documentated

chest pain action plan
GPs generally increased prescribing of evidence based medications from time of discharge

Major gap in CR and secondary

prevention management of ACS

patients in rural South Australia

argeted educational intervention can

improve management of patients post-ACS

Improvements evident in:

- Evidence based prescribing

- Communication between patient/carer 7 GP

- Referrals to CR
- No documentation of special/additional services for ATSI population

- Lifestyle and behavioural risk poorly

documented except smoking status (76\%)

and hypertension and diabetes ( $82 \%$

and $78 \%$

response rate

MMAT: $50 \%$
- Accuracy of sample representation not documented

- Based on medical record documentation and GP survey

- Potential for Hawthorne effect

- Low response rate of eligible GPs MMAT: $75 \%$ 
patients compared to patients that received usual care $(p=0.05)$, and high rates of aspirin $(p=0.03)$ and $\beta$ blocker $(p=0.05)$ continuation among those prescribed these medications at discharge $(n=344)$. The intervention described in Scott et al. [31] also received generally positive feedback from patients.

In addition, Wai et al. [20] reported baseline results of medication use across Australia before a quality improvement initiative. This study reported that only $48 \%$ of patients used four or more evidence-based drugs at a median of 96-day follow-up $(n=1319)$. When medication was stopped post-discharge, "the GP stopped it" was a major reason cited for discontinuation. The subsequent study to these baseline findings [32] did not report any medication usage rates in follow-up.

Two studies examined rates of lipid-lowering therapy (LLT) use in primary care follow-up. Mudge et al. [33] found that $66 \%$ of post-ACS patients were on LLT $6-18$ months post-discharge, and that $18 \%$ of post-ACS patients with cholesterol levels over target did not receive LLT $(n=282)$. Toms et al. [34] measured a $50 \%$ LLT prescription rate 18-36 months post-discharge, and that more than $50 \%$ of study participants had total serum cholesterol levels above target $(n=93)$.

\section{Behaviour change}

Five studies described behaviour change related to ACS in primary care. Gallagher et al. [35] studied an allfemale population to determine predictors of completion of CR $(n=196)$. This descriptive study surveyed patients 12 weeks post-discharge, and found that two-thirds of women were referred to $C R$, and that $C A B G$ patients were more likely to be referred to $\mathrm{CR}$ than were myocardial infarction (MI) patients (though statistical analysis was not provided).

Rushford et al. [36] examined Australian female ACS patients and reported that recall by patients of CR referral by physicians, physiotherapists, nurse practitioners, or dietitians was correlated with attendance $(p=0.001)$ in this cohort $(n=212)$. Schulz et al. [37] found CR referral to be the single biggest influencer of attendance, and also found that being younger $(p=0.032)$ or married $(p=0.03)$ or living with a partner $(p=0.05)$ made patients more likely to be referred to CR $(n=79)$. Gender was not determined by this study to be a factor influencing CR attendance. Toms et al. [34] compared CR participants with non-participants in a observational study, and found that non-participants cited non-referral most commonly as the reason for their non-attendance, and that younger patients were more likely to be participate in CR. In results from a 2012 Australia-wide quality improvement study [32], both GPs and patients reported a $6 \%$ increase in CR referral by GPs post-educational intervention $(n=636$, p-values $=0.05$ and 0.001 for GPs and patients, respectively).

The same interventional study examined the effect of an education intervention across the continuum of care on patients' possession of an ACS management plan [32], which is an evidence-based guideline recommended for all post-ACS patients [5]. Compared to baseline, Peterson et al. [32] found that more patients had documented ACS management plans $(n=1589, p=0.01)$, and of these, more plans contained a chest pain action plan $(n=1383, p<0.0001)$. This intervention also increased communication of this management plan to the GP $(n=1589, p=0.0001)$.

\section{Psychological assessment}

Psychological management in primary care was described in four studies. Fernandez et al. [38] described significant levels of depression, anxiety and documented stress in an observational study of patients $12-18$ months after a percutaneous coronary intervention (PCI) $(n=202)$. Reddy et al. [39] described a lack of consistency in GP adherence to a protocol regarding depression screening, and that in a study of GPs, "about half" of the GPs were prepared to prescribe antidepressants $(n=18)$. In this same study, few GPs asked patients about depression, despite having received information about their patient's depression score. Wachtel et al. [40] found that no ACS patients received any relevant behavioural interventions by a GP $(n=55)$, and no ACS patients received a social support or living condition intervention by a GP $(n=45)$. A randomised controlled trial conducted by Schrader et al. [41] documented that a GP intervention involving a telephone consult with a psychiatrist was the most effective psychological intervention and resulted in a reduced relative risk of having moderate to severe depression (n-237, $95 \%$ CI). The same study found that non-consent to study procedures was associated with being older $(p<0.001)$ and female $(p<0.001)$.

\section{Lifestyle management}

Seven studies discussed management of lifestyle and behavioural risk factors. Fernandez et al. [38] documented that $46 \%$ of female and $25 \%$ of male patients had two or more modifiable risk factors one year after a PCI $(n=202)$. The same study found that patients underestimated their possession of risk factors: for both hypertension and hypercholesterolaemia, the portion of patients that reported these conditions were $9 \%$ and $40 \%$ lower than the portion of patients who had blood pressure and total cholesterol levels above target, respectively [38].

One study in Canberra reported that $12 \%$ of CR participants, $53 \%$ of CR non-participants, and $28 \%$ of all studied patients still smoked 18-36 months after an MI 
( $n=93)$ [34]. Another observational study in Sydney [38] reported that $15 \%$ of PCI patients were active smokers at 12- to 18- month follow-up post-PCI. A crosssectional study in Auckland $(n=202)$ [27], found that $52 \%$ of smokers had quit 3 years post-discharge from an ACS after an implicit intervention by the GP, resulting in an $11 \%$ decrease in smoking in the study population.

A cohort study conducted by Wachtel et al. [29] reported that $45 \%$ of patients received a smoking intervention in their GP clinics, while none received this intervention in the hospital setting $(n=34)$. A larger cross-sectional study [42] found that $88 \%$ of post-ACS smokers received advice to quit $(n=674)$. One crosssectional study [30] reported a significant improvement of smoking cessation at 3- and 6- month post- ACS event ( $n=89$ and $n=104$, respectively) after a quality improvement program which included an education intervention targeting hospitals and GPs ( $p \leq 0.05$ for both).

A qualitative study [43] which described how Australian smokers and ex-smokers viewed the role of their GPs post-ACS found that many of the participants expressed a negative reaction to GP advice about smoking cessation, especially when it was unsolicited $(n=41)$. Some participants expressed that smoking advice was hard to receive when they were unwell or frightened. Patients in the study expressed feeling distressed when GPs attributed all their health problems to smoking, and some admitted to lying to their GP about quitting. Participants often described the manner in which GPs spoke to them about smoking cessation as significant: doctors who had quit smoking or had personal experiences with smoking were more likely to be persuasive.

Other studies described management of physical activity in primary care. The observational study conducted by Fernandez et al. [38] documented that $12 \%$ of patients performed no physical activity 12-18 months after a PCI $(n=202)$, while the Toms et al. study [34] found that $65 \%$ of MI patients exercised less than 3 times a week 18-36 months post-MI $(n=93)$. Ford et al. [27] found that in New Zealand, $47 \%$ patients exercised 4 or more times a week 3 years after their ACS event $(n=112)$. Johnson et al. [42] reported that $76 \%$ of patients were told to increase physical activity by a primary care professional $(n=4330)$, while another study [40] found that only $3 \%$ of patients had an intervention in their GP clinic regarding physical activity $(n=34)$.

Fernandez et al. [38] reported $18 \%$ of patients had hypercholesterolaemia $12-18$ months after a PCI $(n=200)$. A cross-sectional study [27] showed a $0.8 \mathrm{mmol} / \mathrm{L}$ decrease in total cholesterol levels 3 years after ACS discharge $(P<0.001)$ compared to pre-PCI values $(n=112)$. One study found that $60 \%$ of patients received advice in a primary care setting to follow a modified fat diet $(n=4347)$ [42] while another found that only $6 \%$ of patients $(n=34)$ reported receiving advice regarding their dietary habits in a GP clinic [40]. The same study also describes that $7 \%(n=29)$ of patients reported receiving a GP intervention about being obese or overweight, while $3 \%(n=33)$ reported receiving an intervention for alcohol intake.

Besides the four categories outlined by the National Heart Foundation of Australia (NHFA), one study also examined hospital communication as a barrier to primary care management of ACS. As reported by Wai et al. [20], only $77 \%$ of GPs $(n=731)$ reported receiving discharge summaries of ACS patients from hospitals at baseline. In addition, not all discharge summaries included prescribed medications $(88 \%)$ and risk factor management details (55\%). Only $65 \%$ participating in the GP survey considered the quality of hospital information provided as "very good" or "excellent". A subsequent educational intervention did not significantly improve the quality of these discharge summaries [32].

\section{Discussion}

Though adherence to post-ACS management guidelines varied across studies, it is clear that there is much room for improvement in optimising follow-up care following discharge after an acute cardiac event. Reducing morbidity and mortality through adequate secondary prevention would also be financially prudent as it would reduce costs to the health care system. De Guyter and colleagues undertook a cost benefit analysis over a 10 year period which estimated substantial economic and social impacts of increasing the uptake of cardiac rehabilitation and secondary prevention [44]. Compared with a base case of $30 \%$ uptake, increasing uptake of CR to $50 \%$ (scenario 1) or $65 \%$ (scenario 2) gave a benefit cost ratio of 5.6 and 6.8 which translated to net financial savings of $\$ 46.7$ million (scenario 1) and \$86.7 million (scenario 2) and a reduction in Disability Adjusted Life Years of 21,117 to 37,565 compared with the base. Given the preeminent role of primary health care in supporting patient care outside of the hospital, this component of the health care system has a role in secondary prevention that is essential to improving outcomes following coronary events and in minimising unnecessary health care costs, and hence the need to examine how well this is being undertaken.

\section{Knowledge of post-ACS GP management}

This review is unique in its summary of the knowledge base of primary care of coronary artery disease post-ACS in Australia and New Zealand. The 19 peer-reviewed publications show there is fragmented understanding of postACS care by GPs in Australia and New Zealand. Since the studies are diverse in study design, quality, analytical methods, setting, and time frame, it is difficult to discern 
any emerging patterns. However, some strengths and weaknesses do arise.

Studies of medication prescription rates post-ACS report mostly high rates of antiplatelet therapy prescription $[20,26,27,31]$, with one study reporting an encouraging positive trend in medication prescription over time [26]. However, the prescription rates of other evidence-based medications demonstrate room for improvement, especially angiotensin-converting enzyme inhibitor/angiotensin-II receptor blockers (ACEi/ARBs) and glycerol trinitrate (GTN) spray $[27,28]$. Out of two interventional studies aiming to improve medication prescription rates, only one reported a significant positive impact [31]. The limited number and success of interventional studies and the diverse range of medication prescription rates (as described in Table 3) highlight the need for further research in ways to improve medication prescription by GPs in primary care.

Studies examining CR paid little attention to the role of GPs in influencing CR attendance: only one intervention sought to improve CR referral by GPs [32]. This is a matter of concern, especially since studies reported low referral rates [35, 37] and a strong relationship between referral and attendance [36]. Since studies highlighted that female [35], elderly, and single [37], patients are less likely to be referred to $\mathrm{CR}$, interventions that focus on the needs of these special populations are indicated. In addition, since an educational intervention was found to have a significant positive impact on GP referral to $C R$ and to creation of ACS management plans [32], the wider implementation of this quality improvement initiative has the potential to improve outcomes. Johnson and colleagues strongly recommended that non-referred patients be identified by their GP and be referred to CR and those who were referred but did not attend be identified and encouraged to participate in an alternative home-based CR program [42].

Although Fernandez et al. [38] clearly highlighted the need for psychological management of patients with ACS, there is little consensus or study of psychological assessment in primary care. Two descriptive studies found a complete lack of intervention [29] and inconsistent beliefs regarding depression screening in the primary care setting [39], highlighting an urgent need for more research to enhance primary care psychological management of coronary disease. Both studies also used small sample sizes, so research studying psychological assessment on a larger scale would be advantageous. The single randomised controlled trial that examined depression management found that a telephone consultation with a psychiatrist was effective [41], suggesting that larger scale implementation of this practice in primary care could be effective.

In studies where lifestyle management was studied, the possession of multiple modifiable risk factors post-ACS patients was common [33, 34, 38], while GP advice or intervention regarding these risk factors was inconsistent $[27,42]$ and sometimes severely lacking [40]. One promising interventional study found success in increasing GP interventions regarding smoking cessation post-ACS [30], but the success of these interventions in actually causing patients to quit smoking is still unclear. A qualitative study highlighted the complexity of GP involvement in smoking cessation [43], as advice regarding smoking cessation was not always regarded positively, and opinions were inconsistent regarding the productivity of such advice.

Hypercholesterolaemia management through modified diet advice and LLT was generally lacking [38, 42]. In addition, though body mass index (BMI) was not widely addressed, two studies reported alarming rates of obese and overweight post-ACS patients $[29,38]$, while advice from GPs regarding physical activity was imperfect [42]. Little is known about GP management and advice regarding alcohol intake in the context of post-ACS care. Besides depression management and a single study of a diabetic cohort, included publications failed to address in detail the complexities of handling ACS patients with other relevant comorbidities. Research in this area would assist a GP in adequately managing such complex cases. Surprisingly, there were few studies for whom the provision and effectiveness of lifestyle management advice was assessed, and these had small sample sizes. Concerns regarding the efficacy of GP advice in risk factor modification have the potential to influence the rate at which GPs deliver such advice, and so the development of robust strategy regarding GP advice to reduce patient possession of modifiable risk factors would be beneficial. This is an area where practice nurses with chronic disease expertise and ancillary allied health practitioners working within a general practice setting could offer opportunities for improved patient advice and outcomes.

Wai et al. [20] highlighted a need for increased communication between hospitals and GPs post-ACS. A subsequent quality intervention across the continuum of care was promising [32], and has the potential to improve multiple areas of evidence-based management of post-ACS care.

\section{Special populations}

While Indigenous populations are identifiable as collectively having poorer health status in Australia and New Zealand [45], no published studies focused exclusively on the primary care management of Indigenous populations that have suffered an ACS. This is despite documentation that Indigenous populations of both nations face a disproportionate cardiovascular disease burden and experience culture-specific barriers to care [46]. Besides Indigenous populations, no Australian 
studies examined post-discharge ACS management in any non-Indigenous minority populations, although these groups were better addressed in publications from New Zealand [20, 28, 32]. Rural populations face unique barriers to care, and yet only five studies examined different aspects of patient care and follow-up in this setting. This is noteworthy because a significant portion of both Australia and New Zealand's populations reside in rural areas. In addition, while many included studies reported patient populations that were overwhelmingly male, there was limited analysis of gender-based differences in primary care management of ACS. This is significant because post-ACS care decisions have historically been gendered. Overall, though age- and gender-related data was consistently collected, limited analysis of this data was reported. Overwhelmingly, studies followed patients from hospital rather than focusing on GP care. Published literature was also lacking in qualitative data, which could expose underlying attitudes and beliefs that affect patient care.

\section{Study quality}

Out of 17 unique studies, 13 received MMAT scores $\geq$ $75 \%$, indicating that studies were of generally good quality. No study received a score below $50 \%$, though the MMAT score of one study [39] could not be assessed, since its study protocol was not fully reported.

\section{Strengths and limitations}

This review highlights the challenges of and potential opportunities for improvement in post-ACS management in primary care in Australia and New Zealand. As ACS management, as specified by the NHFA and the CSANZ [5] and supplemented by the Cardiovascular Therapeutic Guidelines [6], covers such a broad range of treatment and care, this study is unique reporting on the status of primary care management and research in this area. This review is strengthened by its thorough literature search of multiple databases, and by the quality appraisal of publications in the MMAT format.

Several factors limit the definitive conclusions that can be drawn from the review. In the literature selection process, the possibility exists that relevant article(s) were not identified by the literature search because of gaps in implemented database search strings, although search strings for each database were developed with careful consideration and input from multiple authors, they were not proofread by any third-party assistant or librarian. The decision to limit this review to peer-reviewed publications additionally creates the potential of publication bias [47], especially since studies of populations often neglected by peer-reviewed publications, like Indigenous or rural populations, may be conducted by organisations that lack the financial means to publish academically.

The mixed-methods nature of the publications obtained from the literature search limited the nature of analysis. A meta-analysis was impossible, because of the inclusion of studies that were qualitative, descriptive, and non-interventional. In addition, studies were often limited in the amount of data that was publicly available: studies sometimes only published significant findings or short reports rather than exhaustive research papers. This data limitation was further complicated by the fact that the aim or research question of included studies often differed drastically from the aim of this review (Table 4). The number of publications also restricted the ability to draw conclusions about areas for improvements across the continuum of care. Studies that describe successful interventions may not apply in special population groups, but since special populations were largely not addressed, it is difficult to determine the success of interventions for them. The limited number of publications suggests that more follow-up data or research in this area is required.

The coverage of the subject matter of these publications was also restricted in regard to barriers and facilitators to primary care management of ACS, because the studies do not include patients that were prevented by some means from accessing a GP in the first place.

\section{Conclusions}

Primary care management of post-ACS patients is proven to increase the quality of patients' lives, and reduce their risk of a secondary cardiac event and healthcare system costs of rehospitalisation. Understanding management in primary care and identifying gaps is essential to improving the quality of care for a common, serious, cardiovascular condition where unnecessary readmissions can be avoided. Given high rates of CVD, relatively few papers were identified regarding management in primary health care settings after an acute coronary syndrome event. This is surprising given the importance of support for patients at this time, specifically around adherence to evidence based medications and adopting a healthy lifestyle in order to reduce the chances of a recurrence. There were few interventional studies, so further research of ways to improve quality of care is clearly indicated. Future study should include efforts to improve the quality of care of special population groups must be customised to their particular needs [46]. It is clear that greater integration of hospital and GP management in the form of detailed discharge summaries and communication of management plans would allow for more effective patient care. 


\section{Additional file}

Additional file 1: Search strategy and keywords. Terms used in the literature search. (DOCX 27 kb)

\section{Abbreviations}

ACEi/ARB: Angiotensin-converting enzyme inhibitor/angiotensin-II receptor blocker; ACS: Acute coronary syndrome; BMI: Body mass index; CABG: Coronary artery bypass grafting; CR: Cardiac rehabilitation; CSANZ: Cardiac Society of Australia and New Zealand; CVD: Cardiovascular disease; DAPT: Dual antiplatelet therapy; EBM: Evidence-based medication; HDL: High-density lipoprotein; LDL: Low-density lipoprotein; LLT: Lipidlowering therapy; MeSH: Medical subject headings; MI: Myocardial infarction; MMAT: Mixed methods appraisal tool; NHFA: National Heart Foundation of Australia; NSTEMI: Non-ST-segment elevation myocardial infarction; NZ: New Zealand; PCl: Percutaneous coronary intervention; QI: Quality improvement; RCT: Randomised controlled trial; STEMI: ST-segment elevation myocardial infarction; $\beta$ B: Beta-blocker

\section{Acknowledgements}

Not applicable.

\section{Funding}

Not applicable.

\section{Availability of data and materials}

Not applicable.

\section{Authors' contributions}

All authors contributed to the conception and design of the study. The literature search was undertaken by MB with assistance from JW and both screened papers against inclusion and exclusion. All authors participated in extracting and tabulating data from included publications. MB drafted the manuscript, which was reviewed and revised by all authors. All authors have approved the final version.

\section{Competing interests}

The authors declare that they have no competing interests.

\section{Consent for publication}

Not applicable.

Ethics approval and consent to participate Not applicable.

Received: 31 January 2016 Accepted: 29 October 2016

Published online: 09 November 2016

\section{References}

1. Moretti C, D'Ascenzo F, Omede P, Sciuto F, Presutti DG, Di Cuia M, Colaci C,


a metropolitan center in Europe: incidence and impact on prognosis. J Cardiovasc Med (Hagerstown). 2015:16(3):238-45

2. Chew DP, Briffa TG. The clinical care standards in ACS: towards an integrated approach to evidence translation in ACS care. Heart Lung Circ. 2015;24(3):213-5

3. Brown JP, Clark AM, Dalal H, Welch K, Taylor RS. Patient education in the management of coronary heart disease. Cochrane Database Syst Rev. 2011; (12):Cd008895

4. Anderson L, Oldridge N, Thompson DR, Zwisler AD, Rees K, Martin N, Taylor RS. Exercise-Based Cardiac Rehabilitation for Coronary Heart Disease: Cochrane Systematic Review and Meta-Analysis. J Am Coll Cardiol. 2016; 67(1):1-12.

5. National Heart Foundation of Australia, Cardiac Society of Australia and New Zealand. Reducing risk in heart disease: an expert guide to clinical practice for secondary prevention of coronary heart disease. Melbourne: National Heart Foundation of Australia; 2012

6. Cardiovascular Expert Group. Therapeutic Guidelines: Cardiovascular Version 6. Melbourne: Therapeutic Guidelines Limited; 2012.
7. National Heart Foundation of Australia. Secondary Prevention of Cardiovascular Disease. Melbourne: National Heart Foundation of Australia; 2010.

8. Briffa T, Kinsman L, Maiorana A, Zecchin R, Redfern J, Davidson P, Paull G, Nagle A, Denniss A. An integrated and coordinated approach to preventing recurrent coronary heart disease events in Australia. Policy statement from the Australian Cardiovascular Health and Rehabilitation Association. Med J Aust. 2009;190:683-6.

9. Woodruffe S, Neubeck L, Clark R, Gray K, Ferry C, Finan J, Sanderson S, Briffa T. Australian Cardiovascular Health and Rehabilitation Association (ACRA) Core Components of Cardiovascular Disease, Secondary Prevention, and Cardiac Rehabilitation 2014. Heart Lung Circ. 2015:24:430-41.

10. Joynt KE, Huynh L, Amerena JV, Brieger DB, Coverdale SG, Rankin JM, Soman A, Chew DP. Impact of acute and chronic risk factors on use of evidence-based treatments in patients in Australia with acute coronary syndromes. Heart. 2009;95(17):1442-8.

11. Voller H, Reibis R, Pittrow D, Jannowitz C, Wegscheider K, Karmann B, Bestehorn K. Secondary prevention of diabetic patients with coronary artery disease in cardiac rehabilitation: risk factors, treatment and target level attainment. Curr Med Res Opin. 2009:25(4):879-90.

12. Vickery A, Thompson PL. Eight challenges faced by general practitioners caring for patients after an acute coronary syndrome. Med J Aust. 2014; 201(10):S110-114.

13. Eagle KA, Kline-Rogers E, Goodman SG, Gurfinkel EP, Avezum A, Flather MD, Granger CB, Erickson S, White K, Steg PG. Adherence to evidence-based therapies after discharge for acute coronary syndromes: an ongoing prospective, observational study. Am J Med. 2004;117(2):73-81.

14. Duckett S, Willcox S. The Australian Health Care System. 4th ed. South Melbourne: Oxford University Press; 2011.

15. World Health Organization. New Zealand Health System Review. (Health Systems in Transition, vol. 4. 2nd ed. Geneva: WHO; 2014

16. Australian Institute of Health and Welfare. Cardiovascular disease: Australian facts 2011. Cardiovascular disease series. Cat. no. CVD 53. Canberra: AlHW; 2011

17. Brown A, Walsh W, Lea T, Tonkin A. What Becomes of the Broken Hearted? Coronary Heart Disease as a Paradigm of Cardiovascular Disease and Poor Health Among Indigenous Australians. Heart Lung Circ. 2005;14(3):158-62.

18. Katzenellenbogen JM, Sanfilippo F, Hobbs M, Briffa T, Ridout S, Knuiman M, Dimer L, Taylor KP, Thompson PL, Thompson SC. Incidence of and case fatality following acute myocardial Infarction in Aboriginal and nonAboriginal Western Australians (2000-2004): A linked data study. Heart Lung Circ. 2010;19(12):717-25.

19. World Health Organization. Global Status Report on Noncommunicable Diseases. Geneva: WHO: 2014.

20. Wai A, Pulver LK, Oliver K, Thompson A. Current discharge management of acute coronary syndromes: baseline results from a national quality improvement initiative. Intern Med J. 2012;42(5):e53-59.

21. Al-Khadra S, Meisinger C, Amann U, Holle R, Kuch B, Seidl H, Kirchberger I. Secondary prevention medication after myocardial infarction: persistence in elderly people over the course of 1 year. Drugs Aging. 2014;31(7):513-25.

22. Clark AM, King-Shier KM, Duncan A, Spaling M, Stone JA, Jaglal S, Angus J. Factors influencing referral to cardiac rehabilitation and secondary prevention programs: a systematic review. Eur J Prev Cardiol. 2013;20:692-700.

23. Pirkis J, Blashki G, Murphy A, Hickie I, Ciechomski L. The contribution of general practice based research to the development of national policy: case studies from Ireland and Australia. Aust NZ Health Policy. 2006;3(4).

24. Redfern J. Expanded cardiac rehabilitation reduces cardiac events over five years. J Physiother. 2011;57(1):57.

25. Pluye P, Robert E, Cargo M, Bartlett G, O'Cathain A, Griffiths F, Boardman F, Gagnon MP, Rousseau MC. Proposal: A mixed methods appraisal tool for systematic mixed studies reviews. 2011. http://mixedmethodsappraisal toolpublic.pbworks.com. Archived by WebCite ${ }^{\oplus}$ at http://www.webcitation. org/5tTRTc9yJ Accessed 1 Sep 2015.

26. Cole JA, Brennan AL, Ajani AE, Yan BP, Duffy SJ, Loane P, Reid CM, Yudi MB, New G, Black $A$, et al. Cardiovascular medication use following percutaneous coronary intervention: the Australian experience. Cardiovasc Ther. 2014:32(2):47-51.

27. Ford JA, Bell J, Edwards C. Are we meeting cardiovascular risk targets 3 years after acute coronary syndrome? An evaluation in West Auckland, New Zealand. N Z Med J. 2011;124(1343):65-75.

28. Looi $\mathrm{KL}$, Chow KL, Looi JL, Lee M, Halliday S, White H, Ellis C. Under-use of secondary prevention medication in acute coronary syndrome patients 
treated with in-hospital coronary artery bypass graft surgery. N Z Med J. 2011;124(1343):18-27.

29. Wachtel TM, Kucia AM, Greenhill JA. Secondary prevention for acute coronary syndrome in rural South Australia: are drugs best? What about the rest? Rural Remote Health. 2008;8(4):967.

30. Hickey A, Scott I, Denaro C, Stewart N, Bennett C, Theile T. Using Clinical Indicators in a Quality Improvement Programme Targeting Cardiac Care. Int J Qual Health Care. 2004;16:111-25.

31. Scott IA, Denaro CP, Bennett CJ, Hickey AC, Mudge AM, Flores JL, Sanders DC, Thiele JM, Wenck B, Bennett JW, et al. Achieving better in-hospital and after-hospital care of patients with acute cardiac disease. Med J Aust. 2004 180 Suppl 10:S83-88.

32. Peterson GM, Thompson A, Pulver LK, Robertson MB, Brieger D, Wai A, Tett SE. Management of acute coronary syndromes at hospital discharge: do targeted educational interventions improve practice quality? J Healthc Qual. 2012;34(1):26-34

33. Mudge AM, Brockett R, Foxcroft KF, Denaro CP. Lipid-lowering therapy following major cardiac events: progress and deficits. Med J Aust. 2001; 175(3):138-40

34. Toms LV, O'Neill ME, Gardner A. Long-term risk factor control after a cardiac rehabilitation programme. Aust Crit Care. 2003;16(1):24-8.

35. Gallagher R, McKinley S, Dracup K. Predictors of women's attendance at cardiac rehabilitation programs. Prog Cardiovasc Nurs. 2003;18(3):121-6.

36. Rushford N, Murphy BM, Worcester MU, Goble AJ, Higgins RO, Le Grande MR, Rada J, Elliott PC. Recall of information received in hospital by female cardiac patients. Eur J Cardiovasc Prev Rehabil. 2007:14(3):463-9.

37. Schulz DL, McBurney H. Factors which influence attendance at a rural Australian cardiac rehabilitation program. Coronary Health Care. 2000;4(3): $135-41$.

38. Fernandez RS, Griffiths R, Juergens C, Davidson P, Salamonson Y. Persistence of Coronary Risk Factor Status in Participants 12 to 18 Months After Percutaneous Coronary Intervention. J Cardiovasc Nurs. 2006;21(5):379-87.

39. Reddy P, Dunbar JA, O'Neil A, Morgan MA, Wolff AM, Janus ED. Depression in acute coronary syndrome: Has the evidence been implemented? Aust J Rural Health. 2008;16(4):245-6.

40. Wachtel T, Kucia A, Greenhill J. Unstructured cardiac rehabilitation and secondary prevention in rural South Australia: does it meet best practice guidelines? Contemp Nurse. 2008;29(2):195-204.

41. Schrader G, Cheok F, Hordacre A-L, Marker J, Wade V. Effect of psychiatry liaison with general practitioners on depression severity in recently hospitalised cardiac patients: a randomised controlled trial. Med J Aust. 2005;182(6):272-6

42. Johnson NA, Inder KJ, Ewald BD, James EL, Bowe SJ. Association between Participation in Outpatient Cardiac Rehabilitation and Self-Reported Receipt of Lifestyle Advice from a Healthcare Provider: Results of a Population-Based Cross-Sectional Survey. Rehabil Res Pract. 2010;2010:541741.

43. Hansen EC, Nelson MR. How cardiac patients describe the role of their doctors in smoking cessation: a qualitative study. Aust J Prim Health. 2011; 17(3):268-73.

44. De Gruyter E, Ford G, Stavreski B. Economic and Social Impact of Increasing Uptake of Cardiac Rehabilitation Services-A Cost Benefit Analysis. Heart Lung Circ. 2016;25(2):175-83.

45. Mitrou F, Cooke M, Lawrence D, Povah D, Mobilia E, Guimond E, Zubrick SR. Gaps in Indigenous disadvantage not closing: a census cohort study of social determinants of health in Australia, Canada, and New Zealand from 1981-2006. BMC Public Health. 2014;14:201.

46. Brown A. Acute coronary syndromes in indigenous Australians: opportunities for improving outcomes across the continuum of care. Heart Lung Circ. 2010;19(5-6):325-36.

47. Rothstein HR, Sutton AJ, Borenstein M, editors. Publication Bias in MetaAnalysis - Prevention, Assessment and Adjustments. Chichester: John Wiley \& Sons, Ltd; 2005.

48. Reddy P, Dunbar JA, Morgan MA, O'Neil A. Coronary heart disease and depression: Getting evidence into clinical practice. Stress Health. 2008;24(3): 223-30.

\section{Submit your next manuscript to BioMed Central and we will help you at every step:}

- We accept pre-submission inquiries

- Our selector tool helps you to find the most relevant journal

- We provide round the clock customer support

- Convenient online submission

- Thorough peer review

- Inclusion in PubMed and all major indexing services

- Maximum visibility for your research

Submit your manuscript at www.biomedcentral.com/submit

) Biomed Central 